\title{
ANALYSIS OF THE EXPECTED CROSS AISLE TRAVEL DISTANCE FOR MULTI-PICKS AND MULTI-AISLES CONDITIONS
}

\author{
Agung Chandra ${ }^{1 *}$ \\ *l Faculty of Engineering, Department of Industrial Engineering, University of Mercubuana Jl. Raya Meruya Selatan \\ no.01, Kembangan, Jakarta Barat 11650, Indonesia Email: agung.chandra@mercubuana.ac.id; \\ agungchandra_07@yahoo.co.uk
}

*Corresponding Author: -

Email: agung.chandra@mercubuana.ac.id; agungchandra_07@yahoo.co.uk

\begin{abstract}
: -
Purpose: The purpose of this research is to find the impacts of multi picks multi aisle on expected cross aisle travel distance for one picker at layout with parallel picking aisles and orthogonal cross aisles at each end of the picking aisles. Design / methodology / approach: Using the theory of expected mean value to calculate expected number of cross aisle width in multi-picks and multi-aisles conditions

Findings: the results show that the expected cross aisle travel distance is affected by the expected number of aisle width and number of picks

Research limitations / implications: Further research is needed to explore the other type of layout in order to get the shortest distance. Secondly, the further research needs to analyze the picking activity is done by more than one picker

Practical implications: This is the early beginning study to get the shortest cross aisle travel distance that may be used for professional engineer to design and to choose the best layout for the condition - multi-picks and multi-aisles conditions

Originality / value: This study shows the impact of number of aisle width and number of picks on the cross aisle travel distance by using the theory of expected mean value
\end{abstract}

Keywords: Multi-Picks, Multi-aisles, Expected cross aisle distance.

\section{(a) $(\$)$}




\section{INTRODUCTION}

As more and more companies are pursuing to compete in reaching global market, they think to reduce costs and to increase value which called productivity. All parts of the companies including warehouse need to contribute that precious moment. There are 2 main processes in warehouse, inbound processes: receiving and put away; and outbound processes: order picking, checking, packing and shipping, and the most labour-intensive activity is order picking (Bartholdi \& Hackman, 2011 , p.23 - 24) and order picking process is in general one of the most time-consuming processes and contributes for a large extent to warehousing cost (Roodbergen \& de Koster, 2001). Order picking can be classified into two types: pickerto-stock systems and stock-to-picker systems, in picker-to-stock systems, the picker travels by walking or riding to storage locations to retrieve items; on the other side, stock-to-picker systems, the container or the storage location housing requested item is mechanically brought to the picker for retrieval. Thus, the picker's travel is replaced by the container's travel in stock-to-picker systems (Park: 2012). Order picking system design involves several decisions, such as number of storage locations, layout of picking area, storage policy and configuration, required throughput, picking method (manual, semi-automated, or fully automated), material handling system, and supporting information technology infrastructure (Wallace-Finney, 2011). The majority of warehouses employs humans for order picking. From the total order picking time spent, travel activity is the major one (Dukic \& Oluic, 2007) which is indicated on this graph below:

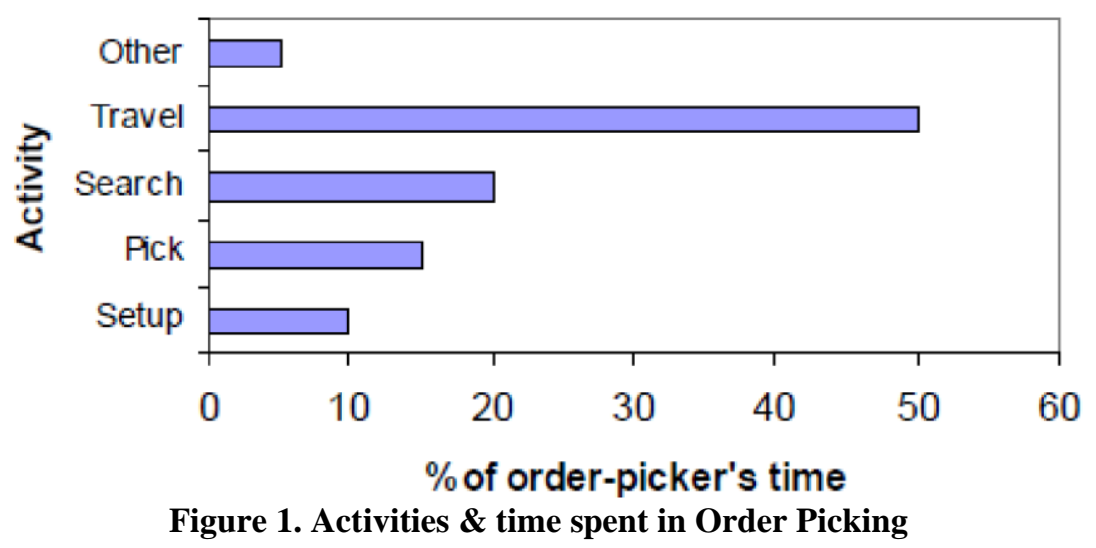

Layout of the picking area includes determination of picking and processing areas, aisle configuration, location of the depot, and material handling flow patterns, among these, aisle configuration is the key as it is reflective of the traveling required by pickers in executing their picking activities, which in turn affects their productivity and system throughput (Wallace-Finney, 2011).

For this reason, it is important to reduce the travel time, and reducing travel time means reducing travel distance. Factors that affects travel time are routing, storage, batching, zoning, and order release mode (Goetschalckx \& Ashayeri, 1989). Travel time is affected by number of aisles, length of the aisle, cross aisle, number of locations picked, and number of pickers.

It becomes interest to research further on number of locations and number of picks for the layout which has parallel picking aisles and orthogonal cross aisles at each end of the picking aisles.

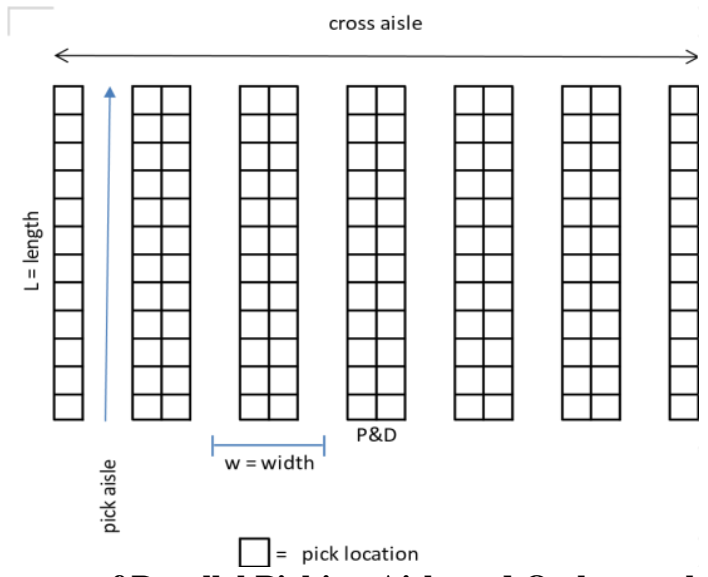

Figure 2. Layout of Parallel Picking Aisle and Orthogonal Cross Aisle

It is assumed that this layout has optimal P\&D location in the bottom centre; picking activity is uniformly distributed within and among the aisles. All pick aisle has the same length and the same width. The warehouse has a set of discrete picking aisles with continuous picking activity in each aisle. The picker has to pick the items according to the pick list, and the pick location can be different and can be the same aisle or combinations of these two. The picker is travelling the pick location by using routing method, S-Shape. Previous research has considered the aspects of number of aisles and cross aisle (Roodbergen, 2006) and aisle configuration (Gue and Meller, 2006), both of these has not considered the 
effects of aisle width. Previous research on dual command operations has shown that two picks can be occurred in different aisle or in the same aisle or combinations of these (Pohl et al, 2009). The extended problem can be more than two picks in several aisles, the combinations are two picks in aisle 1 and one pick in aisle 2 , or three picks in aisle 2 and one pick in aisle 1, and so on. The expected travel distance for this layout is the expected cross aisle plus the expected picking aisle travel distance.

\section{Purpose}

The purpose of this research is to find the effects of multi picks multi aisle on expected cross aisle travel distance for one picker at layout with parallel picking aisles and orthogonal cross aisles at each end of the picking aisles.

\section{Methodology}

\section{Calculation of the expected cross aisle travel distance}

This distance is affected by the number of aisle width and the width itself. The pick lists contain items that have to be picked by the pickers. These items may be located in the same aisle or different aisle. The notation for the pick will be given by $\mathrm{p}$, the notation for the aisle will be given by a, the cross aisle will be given by $\mathrm{c}$.

If one does some picks in some aisles, there will be several possibilities combinations, for example: two picks in three aisles, possible combinations will be $11,22,33,12,21,13,31,23,32$. Combinations 11 means the first pick in first aisle, and the second pick in the first aisle too; 13 means the first pick in the first aisle, and the second pick in the third aisle, etc.

For the cross-aisle width, there will be some categories for two picks in three aisles:

- No cross aisle: $11,22,33$

- One cross aisle: $12,21,23,32$

- Two cross aisles: 13, 31

Then, the total combinations are 9 .

For more details, these will be describing as follow:



Figure 3. Layout for $1^{\text {st }}$ pick in the $2^{\text {nd }}$ aisle and the $2^{\text {nd }}$ pick in the $3^{\text {rd }}$ aisle

In this research, width $(\mathrm{W})=3$ meter, pick length $(\mathrm{L})=12$ meter

Summary for two picks in the three aisle will be on the following table:

Table 1. Summary 2 picks -3 aisles

\begin{tabular}{|l|l|l|}
\hline & 3 aisles & Combinaations from the aisles \\
\hline no cross aisle $(c=0)$ & 3 & $11 ; 22 ; 33$ \\
\hline one cross aisle $(c=1)$ & 4 & $12 ; 21 ; 23 ; 32$ \\
\hline two cross aisles $(c=2)$ & 2 & $13 ; 31$ \\
\hline Total & 9 & \\
\hline
\end{tabular}

Expected number of cross aisle width will be following the theory probability:

$$
\begin{aligned}
& E[H(X)]=\sum_{\text {alli }} H\left(x_{i}\right) \cdot p\left(x_{i}\right) \quad \text { for X discrete } \\
& E_{n c}=\frac{(0 x 3)+(1 x 4)+(2 \times 2)}{3+4+2}=\frac{0+4+4}{9}=\frac{8}{9}
\end{aligned}
$$


And, the expected cross aisle travel distance will be:

$$
E_{d c}=W \times E_{n c} \quad E_{d c}=3 \times \frac{8}{9}=\frac{24}{9}=2.67 \text { meter }
$$

Data Analysis and Findings

Now, the focus is to find the expected cross aisle travel distance for multi picks - multi aisles conditions by using the above principles. First, for the case 3 picks - multi aisles then continue to 4 picks - multi aisles, etc. The details are summarized below:

Table 2. Summary two picks - multi aisles conditions

\begin{tabular}{|l|l|l|l|l|l|}
\hline 2 Picks conditions & \multicolumn{5}{l}{ Number of aisles - a } \\
\hline Number of cross aisles width & 2 aisles & 3 aisles & 4 aisles & 5 aisles & 6 aisles \\
\hline no cross aisle $(\mathrm{c}=0)$ & 2 & 3 & 4 & 5 & 6 \\
\hline one cross aisle $(\mathrm{c}=1)$ & 2 & 4 & 6 & 8 & 10 \\
\hline two cross aisles $(\mathrm{c}=2)$ & & 2 & 4 & 6 & 8 \\
\hline three cross aisles (c=3) & & & 2 & 4 & 6 \\
\hline Four cross aisles (c=4) & & & & 2 & 4 \\
\hline Five cross aisles (c=5) & & & & & 2 \\
\hline Total combinations & $\mathbf{4}$ & $\mathbf{9}$ & $\mathbf{1 6}$ & $\mathbf{2 5}$ & $\mathbf{3 6}$ \\
\hline Expected number of aisle width & $\mathbf{0 . 5 0}$ & $\mathbf{0 . 8 9}$ & $\mathbf{1 . 2 5}$ & $\mathbf{1 . 6 0}$ & $\mathbf{1 . 9 4}$ \\
\hline Expected cross aisle travel distance & $\mathbf{1 . 5 0}$ & $\mathbf{2 . 6 7}$ & $\mathbf{3 . 7 5}$ & $\mathbf{4 . 8 0}$ & $\mathbf{5 . 8 3}$ \\
\hline
\end{tabular}

Table 3. Summary three picks - multi aisles conditions

\begin{tabular}{|l|l|l|l|l|l|}
\hline $\mathbf{3}$ Picks conditions & \multicolumn{5}{l}{ Number of aisles - a } \\
\hline Number of cross aisles width & 2 aisles & 3 aisles & 4 aisles & 5 aisles & 6 aisles \\
\hline no cross aisle $(\mathrm{c}=0)$ & 2 & 3 & 4 & 5 & 6 \\
\hline one cross aisle $(\mathrm{c}=1)$ & 6 & 12 & 18 & 24 & 30 \\
\hline two cross aisles (c=2) & & 12 & 24 & 36 & 48 \\
\hline three cross aisles (c=3) & & & 18 & 36 & 54 \\
\hline Four cross aisles (c=4) & & & & 24 & 48 \\
\hline Five cross aisles (c=5) & & & & & 30 \\
\hline Total combinations & $\mathbf{8}$ & $\mathbf{2 7}$ & $\mathbf{6 4}$ & $\mathbf{1 2 5}$ & $\mathbf{2 1 6}$ \\
\hline Expected number of aisle width & $\mathbf{0 . 7 5}$ & $\mathbf{1 . 3 3}$ & $\mathbf{1 . 8 8}$ & $\mathbf{2 . 4 0}$ & $\mathbf{2 . 9 2}$ \\
\hline Expected cross aisle travel distance & $\mathbf{2 . 2 5}$ & $\mathbf{4 . 0 0}$ & $\mathbf{5 . 6 3}$ & $\mathbf{7 . 2 0}$ & $\mathbf{8 . 7 5}$ \\
\hline
\end{tabular}

Table 4. Summary Four picks - multi aisles conditions

\begin{tabular}{|l|l|l|l|l|l|}
\hline 4 Picks conditions & \multicolumn{5}{l}{ Number of aisles - a } \\
\hline Number of cross aisles width & 2 aisles & 3 aisles & 4 aisles & 5 aisles & 6 aisles \\
\hline no cross aisle (c = 0) & 2 & 3 & 4 & 5 & 6 \\
\hline one cross aisle (c=1) & 14 & 28 & 42 & 56 & 70 \\
\hline two cross aisles (c=2) & & 50 & 100 & 150 & 200 \\
\hline three cross aisles (c=3) & & & 110 & 220 & 330 \\
\hline Four cross aisles (c=4) & & & & 194 & 388 \\
\hline Five cross aisles (c=5) & & & & & 302 \\
\hline Total combinations & $\mathbf{1 6}$ & $\mathbf{8 1}$ & $\mathbf{2 5 6}$ & $\mathbf{6 2 5}$ & $\mathbf{1 2 9 6}$ \\
\hline Expected number of aisle width & $\mathbf{0 . 8 8}$ & $\mathbf{1 . 5 8}$ & $\mathbf{2 . 2 3}$ & $\mathbf{2 . 8 7}$ & $\mathbf{3 . 4 9}$ \\
\hline Expected cross aisle travel distance & $\mathbf{2 . 6 3}$ & $\mathbf{4 . 7 4}$ & $\mathbf{6 . 7 0}$ & $\mathbf{8 . 6 0}$ & $\mathbf{1 0 . 4 7}$ \\
\hline
\end{tabular}




\section{Finding 1}

From table 2 to table 4, number of cross aisle width increases when number of aisle increases, and follows certain trend. For example, for one cross aisle: 14 for two aisles, $28(14+14)$ for three aisles, $42(28+14)$ for four aisles, $56(42+14)$ for five aisles, $70(56+14)$ for six aisles, and one can continue to seven aisles, eight aisles, nine aisles, and so on. The same calculation can be done for other number of cross aisle width.

Table 5. Comparison expected cross aisle travel distance for multi picks - multi aisles

\begin{tabular}{|l|l|l|l|l|l|}
\hline \multicolumn{5}{|l|}{ Number of aisles - a } \\
\hline Number of picks & 2 aisles & 3 aisles & 4 aisles & 5 aisles & 6 aisles \\
\hline 2 Picks & $\mathbf{1 . 5 0}$ & $\mathbf{2 . 6 7}$ & $\mathbf{3 . 7 5}$ & $\mathbf{4 . 8 0}$ & $\mathbf{5 . 8 3}$ \\
\hline 3 Picks & $\mathbf{2 . 2 5}$ & $\mathbf{4 . 0 0}$ & $\mathbf{5 . 6 3}$ & $\mathbf{7 . 2 0}$ & $\mathbf{8 . 7 5}$ \\
\hline 4 Picks & $\mathbf{2 . 6 3}$ & $\mathbf{4 . 7 4}$ & $\mathbf{6 . 7 0}$ & $\mathbf{8 . 6 0}$ & $\mathbf{1 0 . 4 7}$ \\
\hline
\end{tabular}

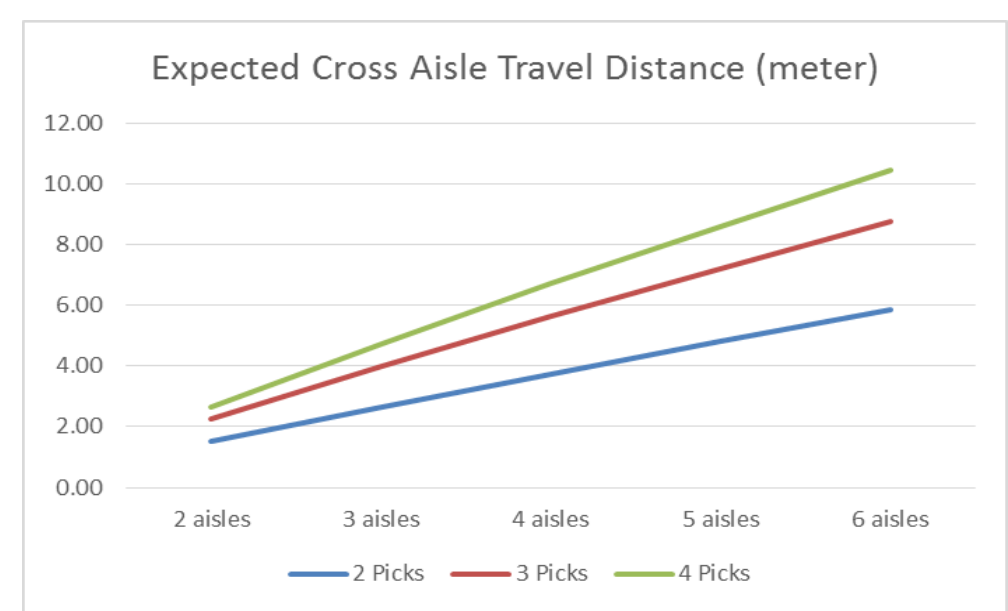

Figure 4. Graphs - comparison multi picks - multi aisle

\section{Finding 2}

From these results, when number of picks increase, then the expected number of aisles width and the expected number of cross travel distance increase. The same thing also happens when number of aisles increase. The cross travel distance is influenced by number of aisle width, number of aisles, and the width itself.

\section{Finding 3}

For the total combinations, the formula can be drawn as follow: $a^{p ;}$ where $\mathrm{a}$ is the number of aisles and $\mathrm{p}$ is the number of picks

\section{Research Limitations and Implications}

This research only focus one type of layout which has no middle cross aisle, then the next research should focus on other type of layout, so the shortest cross aisle travel distance from various layout will be found. The next research can also be conducted with analysis of multi-pickers multi-aisles multi-picks. The simulation method can be applied for this research.

\section{Conclusion}

The expected cross aisle travel distance is affected by number of aisle width, number of picks and the width itself. When number of aisle and number of picks increases, expected cross aisle travel distance increases for this layout.

\section{References}

[1].Bartholdi, J.J, and S.T. Hackman (2011). Warehouse and Distribution Science. Georgia Institute of Technology, available on line: $w$ ww.warehouse-science.com

[2].Dukic, G., and C. Oluic. (2007). Order Picking Methods: Improving Order - Picking Efficiency, International Journal of Logistics System and Management 3 (4), p. $451-460$.

[3].Goetschalckx, M., and Ashayeri, J. (1989). Classification and Design of Order Picking Systems. Logistics World. June, 1989: 99-106.

[4].Gue, K., and Meller, R.D. (2008). Aisle Configuration for Unit Load Warehouse, IIE Transaction.

[5].Hines, W.M. and Montgomery, D.C. (1980). Probability and Statistics in Engineering and Management Science. John Wiley and Sons.

[6].Park, B.C. (2012). Order Picking: Issues, Systems, and Models. Warehousing in the Global Supply Chain, chapter 1.

R. Manzini (ed). Springer - Verlag London Limited.

[7].Pohl, L.M., Russell, D.M., Gue, K.R. (2009). An Analysis of Dual Command Operations in Common Warehouse Design. Transportation Research, An International Journal, part E.45: Logistics and Transportation Review. 
[8].Roodbergen, K.J., and Vis, I.F.A. (2006). A Model for Warehouse Layout. IIE Transaction 38 (10), 20 , p.799-811. [9].Van den Berg, J.P. (1999). A Literature Survey on Planning and Control of Warehousing System. IIE Transaction 31, p.751- 762 .

[10]. Wallace-Finney, S.R. (2011). Determining the Optimal Aisle-Width for Order Picking in Distribution Center. Master Thesis. Wright State University. 